\title{
Increased Serum Concentrations of Circulating Glycocalyx Components in HELLP Syndrome Compared to Healthy Pregnancy: An Observational Study
}

Reproductive Sciences

20(3) 318-325

(C) The Author(s) 2013

Reprints and permission:

sagepub.com/journalsPermissions.nav DOI: I0.1 I77/I9337|9||2453508

rs.sagepub.com

(S)AGE

\author{
Klaus F. Hofmann-Kiefer, MD', J. Knabl, MD², N. Martinoff, MD', \\ B. Schiessl, MD ${ }^{2}$, P. Conzen, MD', M. Rehm, MD', \\ B. F. Becker, $\mathrm{MD}^{3}$, and D. Chappell, MD'
}

\begin{abstract}
Severe inflammation has been shown to induce a shedding of the endothelial glycocalyx (EGX). Inflammatory cytokines, such as tumor necrosis factor $\alpha$ (TNF- $\alpha$ ), impede the thickness of the EGX. While a controlled inflammatory reaction occurs already in normal pregnancy, women with hemolysis, elevated liver enzymes and low platelets (HELLP) syndrome had an exaggerated inflammatory response. This study investigates the shedding of the glycocalyx during normal pregnancy and in women with HELLP syndrome. Glycocalyx components (syndecan I, heparan sulfate, and hyaluronic acid) were measured in serum of healthy women throughout pregnancy (4 time points, $n=26)$, in women with HELLP syndrome $(n=17)$ before delivery and in nonpregnant volunteers $(n=10)$. Serum concentrations of TNF- $\alpha$ and soluble TNF- $\alpha$ receptors (sTNF-Rs) were assessed once in all 3 groups. Syndecan I serum concentrations constantly rose throughout normal pregnancy. Immediately before delivery, a I59-fold increase was measured compared to nonpregnant controls $(P<.0 \mathrm{I})$. Even higher amounts were observed in patients with HELLP prior to delivery (median $12252 \mathrm{ng} / \mathrm{mL}$ ) compared to healthy women matched by gestational age (median $5943 \mathrm{ng} / \mathrm{mL} ; P<.0 \mathrm{I}$ ). Relevantly, increased serum levels of heparan sulfate, hyaluronic acid, and sTNF-Rs were only detected in patients with HELLP ( $P<.0 \mathrm{I})$. These findings suggest that considerable amounts of syndecan I are released into maternal blood during uncomplicated pregnancy. The HELLP syndrome is associated with an even more pronounced shedding of glycocalyx components. The maternal vasculature as well as the placenta has to be discussed as a possible origin of circulating glycocalyx components.
\end{abstract}

\section{Keywords}

endothelial glycocalyx, HELLP syndrome, syndecan I, hyaluronic acid, heparan sulfate

\section{Introduction}

There is constantly growing scientific understanding of the functionality of the endothelial glycocalyx (EGX), which coats the luminal surface of blood vessels. The EGX consists of extracellular domains of molecules such as transmembrane syndecan 1 and membrane-bound glypicans, that both contain covalently bound, highly negatively charged glycosaminoglycans (heparan sulfate and hyaluronic acid). In some regions of the vascular bed, the EGX has proved to be even thicker $(500 \mathrm{~nm})$ than the endothelial cells. ${ }^{1-4}$ A variety of physiological properties has been ascribed to the EGX of which its vital role for vascular integrity and its involvement in immunological processes are certainly most striking. ${ }^{5-16}$ Animal studies have confirmed that tumor necrosis factor $\alpha(\mathrm{TNF}-\alpha)$, usually a proinflammatory mediator substance, can reduce the thickness of the EGX. ${ }^{11,17}$ Experimental and clinical studies have investigated the shedding of the EGX in severe sepsis. ${ }^{12,14,15,18}$ Nelson and coworkers even correlated these increases to overall mortality and the antibacterial actions of plasma. ${ }^{14}$ Some of the physiological processes occurring throughout normal pregnancy have been interpreted as a controlled inflammatory reaction as well. Under pathological conditions, for example, preeclampsia, this usually limited inflammatory response can get out of control. In these cases, endothelial dysfunction occurs, which involves various mediators (eg,

\footnotetext{
I Clinic of Anesthesiology, Ludwig-Maximilians University, City of Munich, München, Germany

${ }^{2}$ Clinic of Gynecology and Obstetrics, Ludwig-Maximilians University, City of Munich, München, Germany

${ }^{3}$ Walter-Brendel-Centre of Experimental Medicine, Ludwig-Maximilians University, City of Munich, München, Germany
}

\section{Corresponding Author:}

Klaus F. Hofmann-Kiefer, Klinik für Anaesthesiologie der Ludwig-Maximilians, Universität München, Klinikum Innenstadt, Maistr. II, 80337 München, Germany. Email: Klaus.Hofmann-Kiefer@med.uni-muenchen.de 
TNF- $\alpha$, interleukin [IL]-2, IL-6, and IL-8), cell adhesion molecules, and leukocytes. ${ }^{19-21}$ Today, the syndrome of hemolysis, elevated liver enzymes, and low platelets (HELLP syndrome) is regarded to be associated with preeclampsia and, besides its typical constellation of laboratory abnormalities, can be accompanied by vascular leakage, disseminated intravascular coagulation, and thrombocyte adhesion. ${ }^{22}$ These pathomechanisms are also known to occur during severe sepsis and to be associated with a destruction of the EGX. ${ }^{23,24}$ However, a possible involvement of the EGX in physiological or pathological processes during pregnancy has not yet been investigated. This study aimed to determine the effect of normal pregnancy and HELLP syndrome on the shedding of the EGX. Moreover, serum concentrations of TNF- $\alpha$ and soluble TNF- $\alpha$ receptors (sTNF-Rs) were measured to detect potential elicitors. ${ }^{17}$

\section{Materials and Methods}

\section{Patients}

Three groups of women were defined to participate in the study

1. Pregnant, otherwise healthy women with a gestational age between weeks 10 and 14 of pregnancy (normal pregnancy group: NP), $\mathrm{n}=26$.

2. Pregnant women with a verified HELLP syndrome (HELLP group: HG), $\mathrm{n}=17$. HELLP syndrome was classified on the basis of platelet count nadir: class I: $<50 \times 10^{9} / \mathrm{L}$, class II: $50 \times 10^{9} / \mathrm{L}$ to $100 \times 10^{9} / \mathrm{L}$, class III $>100 \times 10^{9} / \mathrm{L}$ (Mississippi Triple Class System according to Martin et $\mathrm{al}^{25}$ ). Elevated liver enzymes (aspartate aminotransferase or alanine transaminase $>70 \mathrm{U} / \mathrm{L}$ ) and hemolysis have to be present in any case. To detect hemolysis, haptoglobin serum levels were measured instead of LDH because haptoglobin seems to be the more specific indicator. $^{22,26,27}$

3. Healthy female nonpregnant volunteers aged 27 to 38 years (laboratory control group [CG]), $\mathrm{n}=10$. This group was designed in order to establish normal ranges for serum concentrations of EGX components. Group members were recruited among the department's medical stuff. Age restriction was necessary in order to fit the mean age of the study population as closely as possible.

All women were of European/Caucasian origin. The research protocol was approved by the institutional review board and all women gave written informed consent before enrolment. Women with preexisting and gestational diabetes mellitus, preexisting arterial hypertension, acute or chronic infections, vascular diseases, and/or chronic glucocorticoid therapy were excluded from the study as well as women with prenatal infections and women requiring an emergency section, independent of its cause. None of the women had been given heparin or heparin-like drugs. However, 12 of 17 patients of the HG received glucocorticoids before cesarean section to provide lung maturity of the neonate.

\section{The EGX Components}

Syndecan 1, heparan sulfate and hyaluronic acid, each representing another part of the glycocalyx structure, were measured in maternal serum. ${ }^{2}$ In the NP, blood samples were drawn at weeks $12 \pm 2,20 \pm 2,30 \pm 3,38 \pm 2$ or directly after the beginning of labor, if childbirth occurred unexpectedly before week 38 . In the HG, blood sampling took place immediately before induction of anesthesia for cesarean section. There were no spontaneous deliveries in the HG. In addition, blood samples were collected from 10 women of the CG. Samples were allowed to clot for 30 minutes and afterward cautiously centrifuged (10 minutes at $3000 \mathrm{rpm})$. Serum was stored at $-48^{\circ} \mathrm{C}$ within 15 minutes after the beginning of centrifugation. Commercial enzyme-linked immunosorbent assay (ELISA) kits were used to analyze serum samples according to the manufacturers' manuals (Diaclone SAS, Besançon, France for syndecan 1; Echelon Biosciences Inc, Salt Lake City, Utah for hyaluronic acid; and Seikagaku Corporation, Tokyo, Japan for heparan sulfate). The intra-/interassay variability for the ELISA kits was as follows (\%): syndecan $13.6 / 5.7$; heparan sulfate $6.4 /$ 4.9; hyaluronic acid 7.1/5.0.

\section{TNF- $\alpha$ and $s T N F-R s$}

Serum TNF- $\alpha$ was analyzed with a highly sensitive ELISA kit (sensitivity $0.13 \mathrm{pg} / \mathrm{mL}$, IBL International Corp, Hamburg, Germany). Simultaneously, serum concentrations of sTNFR1 and sTNF-R2 were measured with another ELISA (Wuhan EIAAB Science, Wuhan, China). The intra-assay variability for the ELISA kits was as follows (\%): TNF- $\alpha$ 9.6/9.8; sTNF-R1 5.4/8.9; and sTNF-R2 2.4/3.2. Groups, time points of measurements, and blood processing were as described above for "EGX components" in the HG, CG, and in week $30 \pm 3$ of normal pregnancy.

\section{Statistics}

Mean, standard deviation of the mean, median, and 25th/75th percentile were calculated for each target parameter. To test normality, the Kolmogorov-Smirnov test was applied. Because most of the data were not normally distributed, they are presented as median with 25 th/ 75 th percentile. To describe the changes of EGX components, TNF- $\alpha$ and sTNF-Rs during the course of normal pregnancy, a repeated measurement analysis of variance (ANOVA) on ranks (Friedman test) followed by a Nemenyi test was used. Women of the NP were only included in this intragroup comparison if a complete set of blood samples was available (week 10-38; $\mathrm{n}=18$ ).

In order to compare differences between laboratory values measured in the NP and the HG, a one-way ANOVA on ranks (Kruskal-Wallis test) was followed by Dunn's test. The Spearman rank-order method was applied to work out relevant correlations between target parameters.

The mean gestational age before delivery in the HG was $32.0 \pm 2.8$ weeks. Therefore, we matched serum 
Table I. Demographic and Clinical Data of the Women Enrolled. ${ }^{\mathrm{a}}$

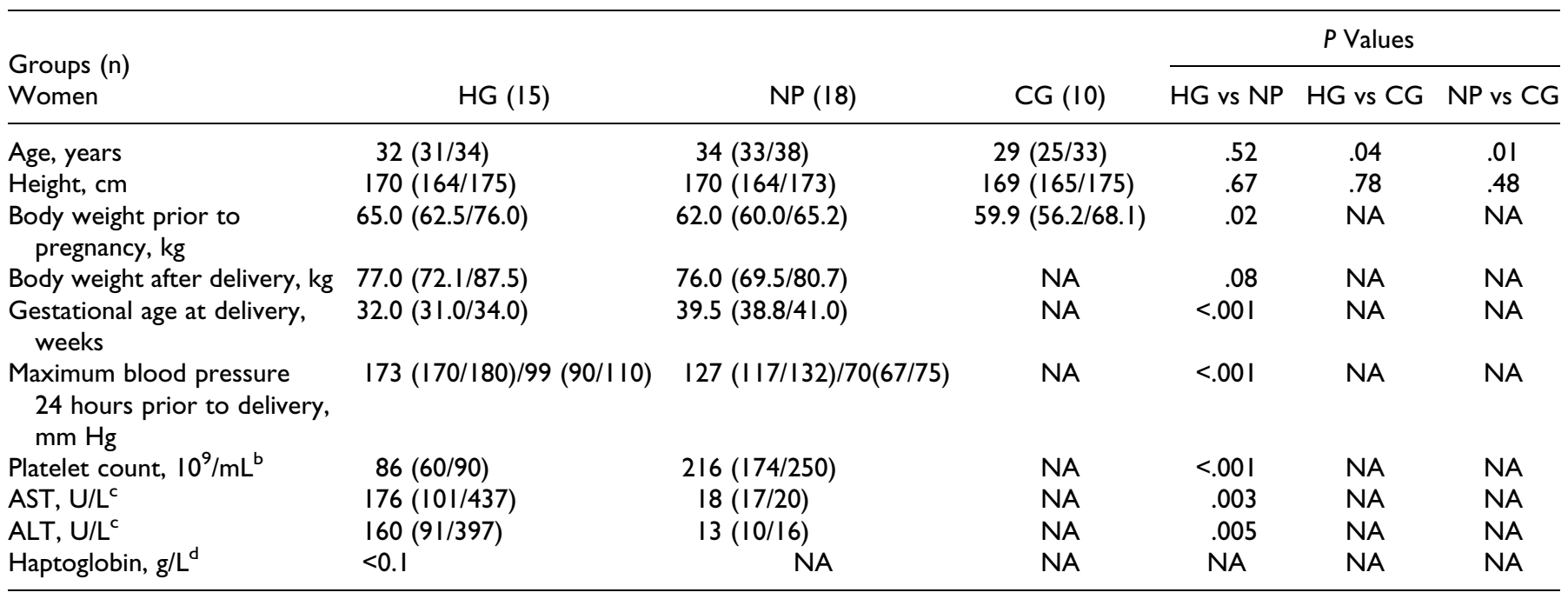

Abbreviations: ALT, alanine transaminase; AST, aspartate aminotransferase; CG, control group; HELLP, hemolysis, elevated liver enzymes and low platelets; HG, HELLP group; NA, not applicable; NP, normal pregnancy group.

${ }^{a}$ Data are given as median with 25 th/75th percentile.

${ }^{b}$ Median was calculated from the lowest values in between I week prior to delivery.

' Median was calculated from the highest values in between I week prior to delivery.

${ }^{d}$ Of the 15 measurements, 12 were below the detection threshold of $0.1 \mathrm{~g} / \mathrm{L}$. They were calculated as $0.09 \mathrm{~g} / \mathrm{L}$.

Table 2. Clinical Data of the Neonates. ${ }^{a}$

\begin{tabular}{|c|c|c|c|}
\hline Groups (n) & HG (I5) & NP (I8) & $P$ Values \\
\hline Body weight, g & $2035(1371 / 2297)$ & $3430(3375 / 3520)$ & $<.001$ \\
\hline Difference to predicted body weight, $g^{\mathrm{b}}$ & +102 & +98 & NA \\
\hline Arterial umbilical cord $\mathrm{pH}$ & $7.30(7.27 / 7.33)$ & $7.40(7.32 / 7.4 I)$ & .09 \\
\hline Arterial umbilical cord BE & $-1.1(-1.9 /-0.2)$ & $-4.1(-4.8 /-3.5)$ & .12 \\
\hline
\end{tabular}

Abbreviations: CG, control group; HELLP, hemolysis, elevated liver enzymes and low platelets; HG, HELLP group; NA, not applicable; NP, normal pregnancy group.

${ }^{a}$ Data are given as median with 25 th $/ 75$ th percentile.

${ }^{b}$ Difference to predicted body weight $(\mathrm{g})$ : difference of the real body weight of the neonates to a predicted birth weight adjusted for gestational age according to Gardosi et al, maternal height, weight, and ethnic origin are taken into account. ${ }^{29}$

concentrations of TNF- $\alpha$, sTNF-Rs, and EGX components of women with HELLP syndrome to the values of healthy pregnant women at week $30 \pm 3$ with gestational age being the matching criterion. Matching was performed manually by a blinded person using the "random order, nearest available pair-matching method." 28 In order to increase the number of possible matching partners for the HG and to achieve a maximal congruency between groups in terms of the matching criterion, every woman who had remained in the NP until week 30 was included in the matching procedure $(n=22)$.

The difference between syndecan 1 serum concentrations between HG and NP (week $30 \pm 3$ ) was considered to be the main outcome variable. After collecting samples from 10 patients $(\mathrm{HG} n=4 ; \mathrm{NP} n=6)$, the differences in means proved to be $5002 \mathrm{ng} / \mathrm{mL}$, the standard deviation of means $4870 \mathrm{ng} /$ $\mathrm{mL}$, leading to a required sample size of 16 women in each group with a type II error protection of $\beta=.8$. For all determinations, a type I error protection of $P<.05$ was considered significant. Statistical analysis was performed using Sigma Stat Software Version 3.1 (Rockware Inc, Golden, Colorado).

\section{Results}

The demographic and clinical characteristics of the women enrolled and the neonates are shown in Tables 1 and 2, respectively. Totally, 17 women were primarily included in the HG. Of all, 12 fulfilled the criteria of a class II, and 3 of a class I HELLP syndrome according to the Mississippi Triple Class System. Two patients with clinical HELLP syndrome were retrospectively excluded, because they did not meet the complete range of laboratory criteria. Severe hypertension $(>160 / 100 \mathrm{~mm} \mathrm{Hg}$ ) was observed in all women of the HG and 9 of 15 patients, in addition to HELLP syndrome, fulfilled the clinical criteria of preeclampsia as recently defined by international protocols (gestational hypertension $>140 / 90 \mathrm{~mm} \mathrm{Hg}$, proteinuria $>0.3 \mathrm{~g} / 24 \mathrm{~h}$ or protein/creatinine ratio $>30 \mathrm{mg} / \mathrm{mmol}) .{ }^{30}$ 


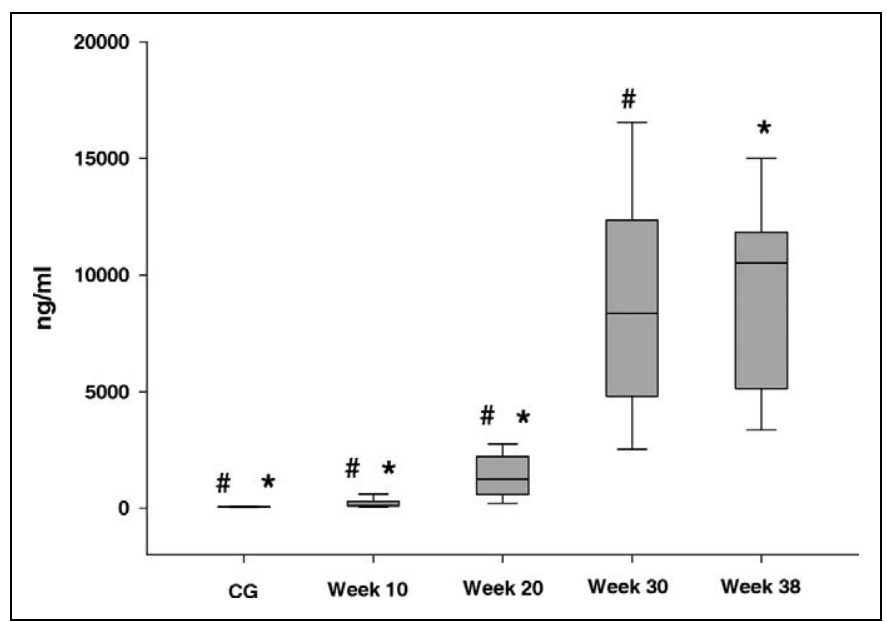

Figure I. Syndecan I serum concentrations during normal pregnancy. Maternal serum concentrations of syndecan I during the course of uncomplicated pregnancy $(\mathrm{n}=18)$. CG: nonpregnant control group. Week 10; 20; 30; 38 (of pregnancy): gestational age of the women enrolled. *Syndecan I serum concentration of CG and pregnancy weeks 10 and 20 differed significantly from week $38 ; P<.01$ for all comparisons. \#Syndecan I serum concentration of CG and pregnancy weeks 10 and 20 differed significantly from week $30 ; P<.01$ for all comparisons.

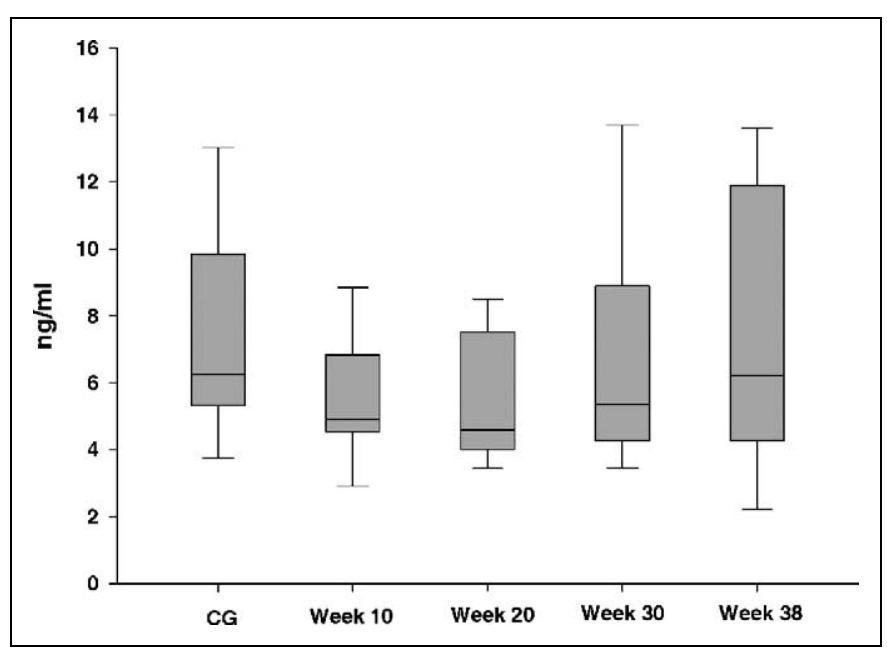

Figure 2. Heparan sulfate serum concentrations during normal pregnancy. Maternal serum concentrations of heparan sulfate during the course of uncomplicated pregnancy $(n=18)$. CG: nonpregnant control group. Week 10; 20; 30; 38 (of pregnancy): gestational age of the women enrolled. No significant differences among groups could be observed.

In all, 26 women were initially included in the NP. During the course of pregnancy, 8 women were excluded (twice premature birth before week 25, 6 women decided to retreat from the study).

\section{The EGX Components}

Changes in serum concentrations of syndecan 1, heparan sulfate, and hyaluronic acid during normal pregnancy are given in Figures 1, 2, and 3, respectively. During pregnancy,

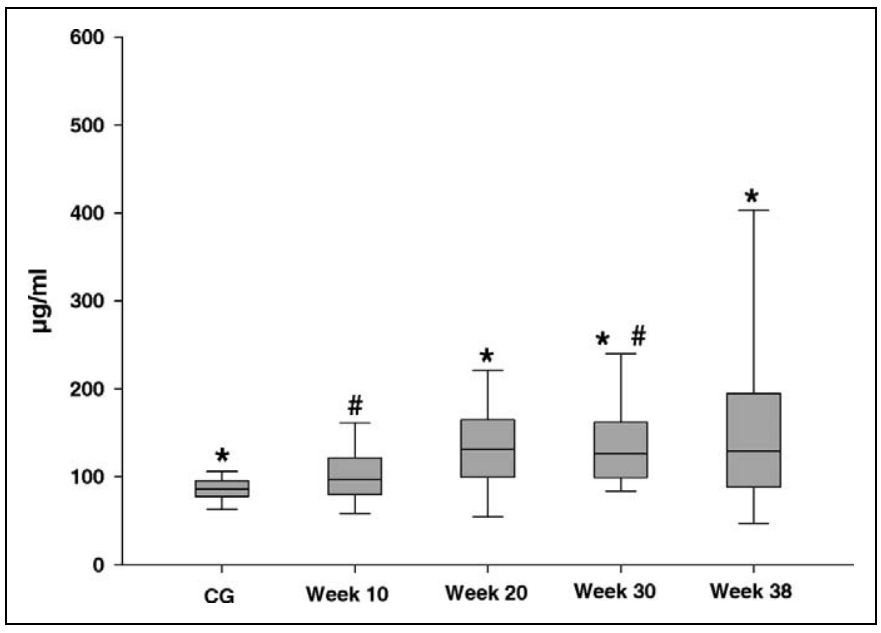

Figure 3. Hyaluronic acid serum concentrations during normal pregnancy. Maternal serum concentrations of hyaluronic acid during the course of uncomplicated pregnancy $(n=18)$. CG: nonpregnant control group. Week 10; 20; 30; 38 (of pregnancy): gestational age of the women enrolled. *Hyaluronic acid serum concentration of CG differed significantly from weeks 20,30 , and 38 ; $P<.05$ for all comparisons. ${ }^{\#}$ Hyaluronic acid serum concentration of pregnancy week 10 differed significantly from week $30 ; P<.05$.

syndecan 1 levels constantly rose, especially between weeks 20 and 30 of pregnancy. Healthy women in late pregnancy showed significantly increased serum concentrations compared to early pregnancy (weeks 10 and 20) and controls. Heparan sulfate serum concentrations remained nearly constant throughout the time course. Concerning hyaluronic acid, a moderate increase was measured between weeks 10 and 20, leading to a significant difference between CG and NP from week 20. In addition, we noticed a relevant intragroup difference between weeks 10 and 30 in NP.

Women with HELLP syndrome showed significantly elevated serum concentrations of all EGX components compared to both healthy pregnant women in week $30 \pm 3$ of pregnancy $(\mathrm{n}=15$ after matching) and nonpregnant women. The corresponding data are given in Table 3.

\section{TNF- $\alpha$ and sTNF-Rs}

Serum levels of TNF- $\alpha$ and its soluble receptors 1 (TNF-R1) and 2 (TNF-R2) were measured in patients with HELLP, in normal pregnancy week $30 \pm 3$ (after matching) and in the CG. Significant differences occurred in HG compared to NP and CG in terms of sTNF-R1 and sTNF-R2. In terms of NP and $\mathrm{CG}$, only the median values of sTNF-R1 differed significantly. Concerning TNF- $\alpha$, no relevant differences among groups were observed (Table 4).

\section{Glucocorticoid Application}

Of the 15 patients in the $\mathrm{HG}, 10$ received glucocorticoids prior to delivery. Doses of $2 \times 12 \mathrm{mg}$ of betamethasone were administered within 48 hours. Time intervals between 
Table 3. Comparison of the Serum Levels of EGX Components Between HELLP Syndrome, Normal Pregnancy Week $30 \pm 3$, and Controls $(\mathrm{CG})^{\mathrm{a}}$

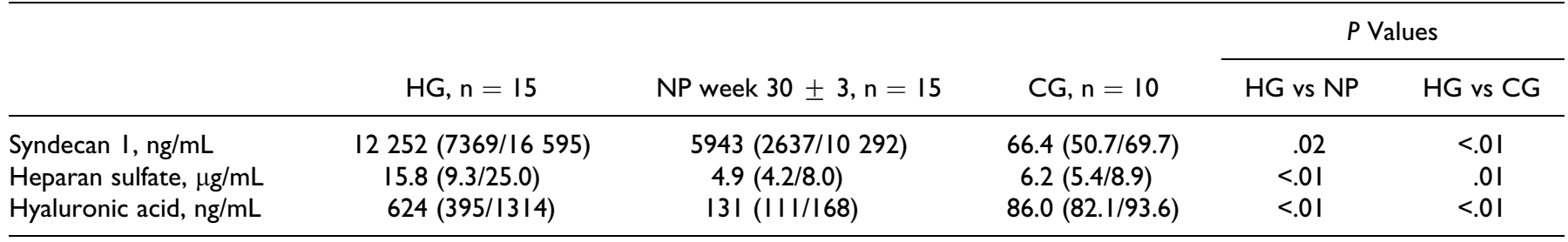

Abbreviations: EGX, endothelial glycocalyx; HELLP, hemolysis, elevated liver enzymes and low platelets; HG, HELLP group; NP, normal pregnancy group.

${ }^{a}$ Data are given as median (25th/75th percentile).

Table 4. Comparison of Serum Levels of TNF- $\alpha$, sTNF-RI, and sTNF-R2 Between HELLP Syndrome, Normal Pregnancy Week $30 \pm 3$, and Controls. ${ }^{\mathrm{a}}$

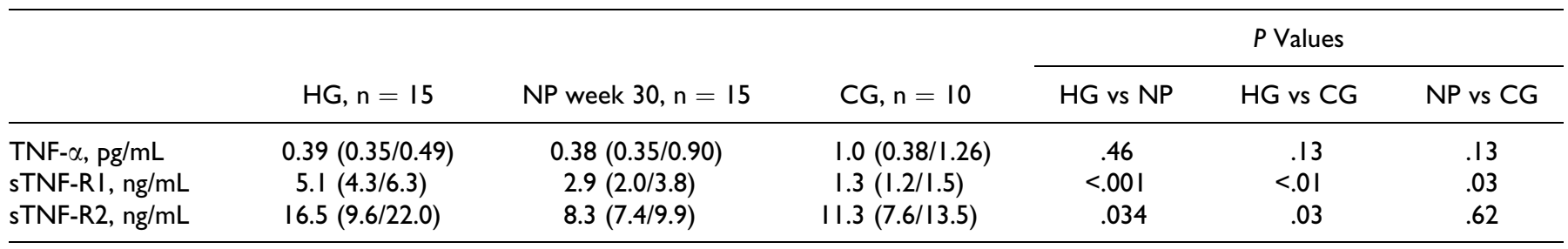

Abbreviations: CG, control group; HELLP, hemolysis, elevated liver enzymes and low platelets; HG, HELLP group; NP, normal pregnancy group; sTNF-Rs, soluble TNF- $\alpha$ receptors; TNF- $\alpha$, tumor necrosis factor $\alpha$.

${ }^{a}$ Data are given as median (25th/75th percentile).

glucocorticoid medication and delivery varied according to clinical requirements ( 1 woman $<6$ hours; 2 women $48-72$ hours; 2 women 96-120 hours; and 5 women 7-41 days). Concerning serum concentrations of TNF- $\alpha$, sTNF-R1, and sTNF-R2, significant differences could not be observed in these subgroups including the group without betamethasone medication $(P>$ .05 for all comparisons).

\section{Discussion}

In the current study, constantly rising serum concentrations of syndecan 1 were measured in healthy pregnant women, even higher amounts were observed in HELLP syndrome. Significantly, elevated serum levels of hyaluronic acid, heparan sulfate, and sTNF-Rs were detected only in patients with HELLP, whereas serum concentrations of TNF- $\alpha$ remained unchanged compared to controls.

\section{Maternal Serum Concentrations of EGX Components}

Control group. The CG of the current study showed values comparable to other investigations in terms of EGX components. ${ }^{14,31-34}$ However, heparan sulfate levels of the CG showed a greater variability than expected (Figure 2). As menstruation is associated with a mild inflammatory response, one cannot exclude that the stage of menstrual cycle of the volunteers (which was not recorded) might have influenced the results in $\mathrm{CG}^{35}$

Uncomplicated pregnancy. Syndecan 1 serum concentrations measured from week 30 proved to be considerably elevated
(Figure 1). Nelson et al, who investigated patients with septic shock, noticed "only" an average of $246 \mathrm{ng} / \mathrm{mL}$ (range 180/ $496 \mathrm{ng} / \mathrm{mL}) .{ }^{14}$ Because of its observational design, the current study is not appropriate to explain this unexpected rise of EGX components in maternal serum. However, even if pregnancy is interpreted to be a form of controlled inflammation, a shedding of the maternal EGX causing syndecan 1 blood levels more than 10-fold higher than in patients with sepsis should have triggered substantial maternal clinical symptoms and/or a variety of uncontrolled immunological reactions. ${ }^{14,36,37}$ Transmembrane syndecan 1 serves as a core protein of the EGX, whereas heparan sulfate and hyaluronic acid chains are attached to it on the luminal surface of the EGX network. ${ }^{2}$ Accordingly, an isolated rise of syndecan 1 has not yet been reported in investigations studying EGX degradation. Elevated levels of hyaluronic acid and/or heparan sulfate have always been detectable, too. Different rates of renal excretion might also have an influence on serum levels of EGX components. However, with regard to molecular mass and charge, there is no reason for the renal clearance of syndecan 1 to be reduced compared to hyaluronic acid or heparan sulfate. ${ }^{1}$ Considering these observations, sources besides the EGX have to be evaluated, which might explain the presence of syndecan 1 in maternal blood. We know that syndecan 1 is strongly expressed on the apical surface of syncytiotrophoblast cells. ${ }^{38}$ The syncytiotrophoblast is involved in the continuous process of degradation and rebuilding the placenta experiences especially between weeks 20 and 30 of pregnancy and thus generates an enormous turnover of cellular material. ${ }^{39}$ According to Redman et al, a large burden of cellular debris originating from the placenta, especially from the syncytiotrophoblast layer, is 
released into maternal blood. ${ }^{40}$ Redman et al proposed the presence of "syncytiotrophoblast microfragments" (STBM). These are detectable in maternal serum in normal pregnancy as well as in preeclampsia. ${ }^{41}$ Goswami et al quantified the maternal serum concentrations of these STBM to be about 16 $\mathrm{ng} / \mathrm{mL}$ in normal pregnancy and $41 \mathrm{ng} / \mathrm{mL}$ in early onset preeclampsia. ${ }^{42} \mathrm{We}$ now propose glycocalyx components like syndecan 1 to be a major fraction of STBM and that the amount of these components pervading the maternal circulation is much greater than has previously been assumed. It has been shown that disrupted glycocalyx fragments can activate leukocytes, which, on the other hand, are able to cleave heparan sulfate from syndecans of the EGX. ${ }^{43,44}$ However, whether a fraction of the "syndecan 1 burden" is deriving directly from the maternal EGX cannot be decided on the basis of the current data.

HELLP syndrome. In HG, serum levels of syndecan 1 were nearly twice as high as in NP $(P=.02)$. Interestingly, Jokimaa et al showed a decreased syndecan 1 expression on the chorionic villi of preeclamptic patients. ${ }^{45}$ This, on first sight, speaks against a placental origin of elevated syndecan 1 serum concentrations measured in the HG. However, the diminished expression of syndecan 1 observed by Jokimaa et al might as well have been caused by an increased loss of syndecan 1 into the maternal vasculature as by a reduced placental syndecan 1 "production." Increased syndecan 1 levels in the HG were accompanied by significantly elevated hyaluronic acid and heparan sulfate concentrations (6-fold and 3-fold, respectively) The presence of all 3 measured glycocalyx components in maternal blood would be in better accordance with a maternal endothelial origin, but as in NP, the current data do not allow definitive conclusions to be drawn concerning the source. Despite proteinuria, laboratory measurements did not signalize renal injury in $\mathrm{HG}$ and all but 1 patient displayed a creatinine clearance of more than $120 \mathrm{~mL} / \mathrm{min}$ (data not shown). Thus, similar to NP, there is no obvious reason for EGX serum levels to be elevated because of a potential kidney malfunction. Finally, one has to consider whether arterial hypertension may have induced EGX deterioration in patients with HELLP. According to previous studies, hypertension does not directly provoke endothelial shear stress. ${ }^{46,47}$ However, according to Borghi et al, hypertension in pregnancy can be associated with elevated levels of atrial natriuretic peptide (ANP) which in turn has shown to cause an EGX shedding in isolated arteries of guinea pigs. ${ }^{48,49}$ Because ANP concentrations were not measured, the relevance of these in vitro findings in context with the current study remains unclear.

\section{TNF- $\alpha$ and $s T N F-R s$}

Study results concerning serum levels of TNF- $\alpha$ in preeclampsia are inconsistent. Many, but not all studies report maternal TNF- $\alpha$ concentrations as elevated. ${ }^{50-55}$ Failure to detect TNF$\alpha$ can occur, if time requirements for processing samples are too long with regard to the short biological half-life of TNF- $\alpha$
$(<5$ minutes $){ }^{55}$ Acquisition time may also have been a problem in the current study.

Serum concentrations of sTNF-Rs are considered reliable markers for inflammation, having longer half-lives than the ligand. ${ }^{56} \mathrm{We}$ observed a significant difference in STNF-R1 and sTNF-R2 concentrations in women with HELLP syndrome compared to NP and controls. To our knowledge, increased levels of those receptors have only been described for preeclampsia but have not yet been demonstrated for HELLP syndrome. ${ }^{52,56}$ Glucocorticoid treatment can influence TNF- $\alpha$ and its soluble receptors in different ways: TNF- $\alpha$ and sTNF-R2 production can be inhibited, whereas sTNF-R1 expression is known to be increased. However, the effect of dexamethasone on all these mediators does not exceed an interval longer than 24 hours after glucocorticoid administration and, therefore, should not have influenced cytokine serum concentrations in the current study. ${ }^{57-59}$ Syndecan 1 serum levels were significantly correlated to TNF- $\alpha(r=0.60, P=.02)$, sTNF-R1 $(r=$ $0.67, P<.01)$, and sTNF-R2 $(r=0.59, P=.02)$ in patients with HELLP, but not in NP. A relevant correlation between these cytokines and the other EGX components could not be observed. Thus, data do not clearly demonstrate a relationship between these mediators and an EGX shedding but do speak in favor of an exaggerated inflammatory response in the concerned women.

To date, most investigators consider HELLP syndrome to be associated with preeclampsia. Accordingly, $60 \%$ of the patients in HG fulfilled the diagnostic criteria valid for preeclampsia. Nevertheless, preeclamptic women without HELLP syndrome were not included for the following reasons: today preeclampsia is well defined by international protocols. ${ }^{29,60}$ However, these protocols usually leave space for a variety of clinical manifestations and are partially independent from the severity of the disease. Therefore, integrating solely preeclamptic women probably would have led to an inhomogeneous study population and thus complicating the interpretation of results. In contrast, HELLP syndrome is clearly defined by a set of laboratory values and the concerned women definitely display severe clinical symptoms. Therefore, it seemed advantageous to include only women with HELLP syndrome in the current study, even if this led to relatively small study groups.

\section{Conclusion}

A shedding of the maternal EGX has not yet been described in pregnancy nor has the placenta been considered as a source of glycocalyx fragments. The current study demonstrates that glycosaminoglycans pervading the maternal circulation may play a role in normal pregnancy as well as in HELLP syndrome. Whether the maternal endothelium, the placenta, or other organic structures have to be regarded as the origin of glycocalyx components in maternal serum will have to be investigated in further studies.

\section{Acknowledgments}

We thank Mrs G. Gröger, University of Munich, for her valuable contribution to the laboratory work. 


\section{Declaration of Conflicting Interests}

The authors declared no potential conflicts of interest with respect to the research, authorship, and/or publication of this article.

\section{Funding}

The authors disclosed receipt of the following financial support for the research, authorship and/or publication of this article: noncommercial scientific research funding provided by the Friedrich-Baur-Foundation, Ziemssenstraße 1, 80336 Munich, Germany. Funding was not linked to any influence on study design or manuscript approval.

\section{References}

1. Weinbaum S, Tarbell JM, Damiano ER. The structure and function of the endothelial glycocalyx layer. Annu Rev Biomed Eng. 2007;9:121-167.

2. Pries AR, Secomb TW, Gaehtgens P. The endothelial surface layer. Pflugers Arch. 2000;440(5):653-666.

3. Reitsma S, Slaaf DW, Vink H, van Zandvoort MA, oude Egbrink MG. The endothelial glycocalyx: composition, functions, and visualization. Pflugers Arch. 2007;454(3):345-359.

4. Chappell D, Jacob M, Becker BF, Hofmann-Kiefer K, Conzen P, Rehm M. Expedition glycocalyx. A newly discovered "Great Barrier Reef" [in German]. Anaesthesist. 2008;57(10):959-969.

5. Klein NJ, Shennan GI, Heyderman RS, Levin M. Alteration in glycosaminoglycan metabolism and surface charge on human umbilical vein endothelial cells induced by cytokines, endotoxin and neutrophils. J Cell Sci. 1992;102(pt 4):821-832.

6. Jacob M, Bruegger D, Rehm M, et al. The endothelial glycocalyx affords compatibility of Starling's principle and high cardiac interstitial albumin levels. Cardiovasc Res. 2007;73(3):575-586.

7. Rehm M, Zahler S, Lotsch M, et al. Endothelial glycocalyx as an additional barrier determining extravasation of $6 \%$ hydroxyethyl starch or $5 \%$ albumin solutions in the coronary vascular bed. Anesthesiology. 2004;100(5):1211-1223.

8. Becker BF, Chappell D, Jacob M. Endothelial glycocalyx and coronary vascular permeability: the fringe benefit. Basic Res Cardiol. 2010;105(6):687-701.

9. Mulivor AW, Lipowsky HH. Inflammation- and ischemiainduced shedding of venular glycocalyx. Am J Physiol Heart Circ Physiol. 2004;286(5):H1672-H1680.

10. Mulivor AW, Lipowsky HH. Role of glycocalyx in leukocyteendothelial cell adhesion. Am J Physiol Heart Circ Physiol. 2002;283(4):H1282-H1291.

11. Henry CB, Duling BR. TNF-alpha increases entry of macromolecules into luminal endothelial cell glycocalyx. Am J Physiol Heart Circ Physiol. 2000;279(6):H2815-H2823.

12. Hofmann-Kiefer KF, Kemming GI, Chappell D, et al. Serum heparan sulfate levels are elevated in endotoxemia. Eur $J$ Med Res. 2009;14(12):526-531.

13. Jacob M, Chappell D, Hofmann-Kiefer K, Conzen P, Peter K, Rehm M. Determinants of insensible fluid loss: Perspiration, protein shift and endothelial glycocalyx [in German]. Anaesthesist. 2007;56(8):747-758, 760-764.

14. Nelson A, Berkestedt I, Schmidtchen A, Ljunggren L, Bodelsson M. Increased levels of glycosaminoglycans during septic shock: relation to mortality and the antibacterial actions of plasma. Shock. 2008;30(6):623-627.

15. Marechal X, Favory R, Joulin O, et al. Endothelial glycocalyx damage during endotoxemia coincides with microcirculatory dysfunction and vascular oxidative stress. Shock. 2008;29(5): 572-576.

16. Henrich M, Gruss M, Weigand MA. Sepsis-induced degradation of endothelial glycocalix. Scientific World Journal. 2010;10:917-923.

17. Chappell D, Hofmann-Kiefer K, Jacob M, et al. TNF-alpha induced shedding of the endothelial glycocalyx is prevented by hydrocortisone and antithrombin. Basic Res Cardiol. 2009; 104(1):78-89.

18. Oragui EE, Nadel S, Kyd P, Levin M. Increased excretion of urinary glycosaminoglycans in meningococcal septicemia and their relationship to proteinuria. Crit Care Med. 2000;28(8): 3002-3008.

19. Redman CW, Sacks GP, Sargent IL. Preeclampsia: an excessive maternal inflammatory response to pregnancy 1 . Am J Obstet Gynecol. 1999;180(2 pt 1):499-506.

20. Mellembakken JR, Aukrust P, Olafsen MK, Ueland T, Hestdal K, Videm V. Activation of leukocytes during the uteroplacental passage in preeclampsia. Hypertension. 2002;39(1):155-160.

21. Mellembakken JR, Aukrust P, Hestdal K, Ueland T, Abyholm T, Videm V. Chemokines and leukocyte activation in the fetal circulation during preeclampsia. Hypertension. 2001;38(3):394-398.

22. Haram K, Svendsen E, Abildgaard U. The HELLP syndrome: clinical issues and management. A Review. BMC Pregnancy Childbirth. 2009;9:8.

23. Nieuwdorp M, van Haeften TW, Gouverneur MC, et al. Loss of endothelial glycocalyx during acute hyperglycemia coincides with endothelial dysfunction and coagulation activation in vivo. Diabetes. 2006;55(2):480-486.

24. Vink H, Constantinescu AA, Spaan JA. Oxidized lipoproteins degrade the endothelial surface layer: implications for plateletendothelial cell adhesion. Circulation. 2000;101(13):1500-1502.

25. Martin JN Jr, Rinehart BK, May WL, Magann EF, Terrone DA, Blake PG. The spectrum of severe preeclampsia: comparative analysis by HELLP (hemolysis, elevated liver enzyme levels, and low platelet count) syndrome classification. Am J Obstet Gynecol. 1999;180(6 pt 1):1373-1384.

26. O'Hara Padden M. HELLP Syndrome: recognition and perinatal management. Am Fam Physician. 1999;60(3):829-839.

27. van Runnard Heimel PJ, Franx A, Schobben AF, Huisjes AJ, Derks JB, Bruinse HW. Corticosteroids, pregnancy, and HELLP syndrome: a review. Obstet Gynecol Surv. 2005;60(1):57-70.

28. Smith HL. Matching with multiple controls to estimate treatment effects in observational studies. Sociol Methodol. 1997;27:325-353.

29. Gardosi J, Chang A, Kalyan B, Sahota D, Symonds EM. Customised antenatal growth charts. Lancet. 1992;339(8788): 283-287.

30. Steegers EA, von DP, Duvekot JJ, Pijnenborg R. Pre-eclampsia. Lancet. 2010;376(9741):631-644.

31. Rehm M, Bruegger D, Christ F, et al. Shedding of the endothelial glycocalyx in patients undergoing major vascular surgery with global and regional ischemia. Circulation. 2007;116(17): 1896-1906. 
32. Kim JM, Lee JA, Cho IS, Ihm CH. Soluble syndecan-1 at diagnosis and during follow up of multiple myeloma: a single institution study. Korean J Hematol. 2010;45(2):115-119.

33. Anttonen A, Leppa S, Ruotsalainen T, Alfthan H, Mattson K, Joensuu H. Pretreatment serum syndecan-1 levels and outcome in small cell lung cancer patients treated with platinum-based chemotherapy. Lung Cancer. 2003;41(2):171-177.

34. Parsian H, Rahimipour A, Nouri M, et al. Serum hyaluronic acid and laminin as biomarkers in liver fibrosis. J Gastrointestin Liver Dis. 2010;19(2):169-174.

35. Puder JJ, Blum CA, Mueller B, De GC, Dye L, Keller U. Menstrual cycle symptoms are associated with changes in low-grade inflammation. Eur J Clin Invest. 2006;36(1):58-64.

36. Sargent IL, Borzychowski AM, Redman CW. Immunoregulation in normal pregnancy and pre-eclampsia: an overview. Reprod Biomed Online. 2006;13(5):680-686.

37. Alexopoulou AN, Multhaupt HA, Couchman JR. Syndecans in wound healing, inflammation and vascular biology. Int J Biochem Cell Biol. 2007;39(3):505-528.

38. Jokimaa V, Inki P, Kujari H, Hirvonen O, Ekholm E, Anttila L. Expression of syndecan-1 in human placenta and decidua. Placenta. 1998;19(2-3):157-163.

39. Kingdom J, Huppertz B, Seaward G, Kaufmann P. Development of the placental villous tree and its consequences for fetal growth. Eur J Obstet Gynecol Reprod Biol. 2000;92(1):35-43.

40. Redman CW, Sargent IL. Placental debris, oxidative stress and pre-eclampsia. Placenta. 2000;21(7):597-602.

41. Knight M, Redman CW, Linton EA, Sargent IL. Shedding of syncytiotrophoblast microvilli into the maternal circulation in preeclamptic pregnancies. Br J Obstet Gynaecol. 1998;105(6): 632-640.

42. Goswami D, Tannetta DS, Magee LA, et al. Excess syncytiotrophoblast microparticle shedding is a feature of early-onset preeclampsia, but not normotensive intrauterine growth restriction. Placenta. 2006;27(1):56-61.

43. Gotte M, Echtermeyer F. Syndecan-1 as a regulator of chemokine function. ScientificWorldJournal. 2003;3:1327-1331.

44. Gotte M. Syndecans in inflammation. FASEB J. 2003;17(6): 575-591.

45. Jokimaa VI, Kujari HP, Ekholm EM, Inki PL, Anttila L. Placental expression of syndecan 1 is diminished in preeclampsia. Am J Obstet Gynecol. 2000;183(6):1495-1498.

46. Simon AC, Levenson J, Flaud P. Pulsatile flow and oscillating wall shear stress in the brachial artery of normotensive and hypertensive subjects. Cardiovasc Res. 1990;24(2):129-136.

47. Simon AC, Levenson J. Abnormal wall shear conditions in the brachial artery of hypertensive patients. J Hypertens. 1990;8(2): 109-114.
48. Bruegger D, Jacob M, Rehm M, et al. Atrial natriuretic peptide induces shedding of endothelial glycocalyx in coronary vascular bed of guinea pig hearts. Am J Physiol Heart Circ Physiol. 2005;289(5):H1993-H1999.

49. Borghi C, Cicero AF, Degli ED, et al. Hemodynamic and neurohumoral profile in patients with different types of hypertension in pregnancy. Intern Emerg Med. 2011;6(3):227-234.

50. Kupferminc MJ, Peaceman AM, Wigton TR, Tamura RK, Rehnberg KA, Socol ML. Immunoreactive tumor necrosis factor-alpha is elevated in maternal plasma but undetected in amniotic fluid in the second trimester. Am J Obstet Gynecol. 1994;171(4):976-979.

51. Conrad KP, Miles TM, Benyo DF. Circulating levels of immunoreactive cytokines in women with preeclampsia. Am J Reprod Immunol. 1998;40(2):102-111.

52. Vince GS, Starkey PM, Austgulen R, Kwiatkowski D, Redman CW. Interleukin-6, tumour necrosis factor and soluble tumour necrosis factor receptors in women with pre-eclampsia. $\mathrm{Br} J$ Obstet Gynaecol. 1995;102(1):20-25.

53. Visser W, Beckmann I, Bremer HA, Lim HL, Wallenburg HC. Bioactive tumour necrosis factor alpha in pre-eclamptic patients with and without the HELLP syndrome. Br J Obstet Gynaecol. 1994;101(12):1081-1082.

54. Schipper EJ, Bolte AC, Schalkwijk CG, Van Geijn HP, Dekker GA. TNF-receptor levels in preeclampsia - results of a longitudinal study in high-risk women. J Matern Fetal Neonatal Med. 2005;18(5):283-287.

55. van Runnard Heimel PJ, Kavelaars A, Heijnen CJ, et al. HELLP syndrome is associated with an increased inflammatory response, which may be inhibited by administration of prednisolone. Hypertens Pregnancy. 2008;27(3):253-265.

56. Sibai B, Romero R, Klebanoff MA, et al. Maternal plasma concentrations of the soluble tumor necrosis factor receptor 2 are increased prior to the diagnosis of preeclampsia. Am J Obstet Gynecol. 2009;200(6):630.e1-e8.

57. Fantuzzi G, Demitri MT, Ghezzi P. Differential effect of glucocorticoids on tumour necrosis factor production in mice: upregulation by early pretreatment with dexamethasone. Clin Exp Immunol. 1994;96(1):166-169.

58. Reikeras O, Helle A, Krohn CD, Brox JI. Effects of high-dose corticosteroids on post-traumatic inflammatory mediators. Inflamm Res. 2009;58(12):891-897.

59. Man SF, Xuekui Z, Vessey R, et al. The effects of inhaled and oral corticosteroids on serum inflammatory biomarkers in COPD: an exploratory study. Ther Adv Respir Dis. 2009;3(2):73-80.

60. Report of the National High Blood Pressure Education Program Working Group on High Blood Pressure in Pregnancy. Am J Obstet Gynecol. 2000;183(1):S1-S22. 